\title{
A presença do Banco Mundial e do Banco Interamericano no financiamento do ensino fundamental e médio na Rede Estadual de Ensino do Paraná
}

\section{The financing presence of the World Bank and of the Interamerican Bank on the State of Paraná Education System, from fundamental to high school}

\author{
Maria Dativa de Salles Gonçalves* \\ Jussara Maria Tavares Puglielli Santos* \\ Andréa Barbosa Gouveia* \\ Cleusa Valéria Gabardo* \\ Leila de Almeida de Locco* \\ Pedro Eloy Rech* \\ Sandra Terezinha da Silva* \\ Taís Moura Tavares* \\ Yvelise Freitas de Souza Arcoverde*
}

\begin{abstract}
* Grupo de Pesquisa: Maria Dativa de Salles Gonçalves (Coordenadora), Doutora em Educação pela Pontifícia Universidade Católica - PUC/SP -, professora do Programa de Pós-Graduação em Educação da Universidade Federal do Paraná - UFPR, dativa@ onda.com.br; Jussara Maria Tavares Puglielli Santos (Coordenadora), Doutora em Educação pela Universidade de São Paulo - USP -, professora do DEPLAE/UFPR, jades@ uol.com.br. Equipe: Andréa Barbosa Gouveia, Mestre em Educação pela PUC/SP, professora do DEPLAE/UFPR, andreabg@ufpr.br; Cleusa Valéria Gabardo, Mestre em Educação pela UFPR, professora do DTFE/UFPR, cleusavg@ufpr.br; Leila de Almeida de Locco, Mestre em Educação pela UFPR, locco@ufpr.br; Pedro Eloy Rech, Mestre em Educação pela PUC/sP; Sandra Terezinha da Silva, Mestre em Educação pela UFPR, técnica do Ipardes, sandraterezinha@yahoo.com.br; Taís Moura Tavares, Mestre em Educação pela UFPR, professora do DEPLAE/UFPR, taismour@ufpr.br; Yvelise Freitas de Souza Arcoverde, Doutora em Educação pela PUC/SP, professora do DEPLAE/UFPR, yvelisef@ufpr.br.
\end{abstract}




\title{
RESUMO
}

$\mathrm{O}$ artigo apresenta os resultados de pesquisa sobre os financiamentos internacionais do Banco Mundial (BIRD) e do Banco Interamericano de Desenvolvimento (BID) para o ensino fundamental e médio, no Paraná, nos anos 80 e 90, em três governos do Partido do Movimento Democrático Brasileiro (PMDB) que estiveram no poder de 1983 a 1994. A partir da identificação de que o primeiro governo (1983-1986) encaminha e redireciona, segundo prioridades democráticas ou comunitárias, projetos financiados com recursos externos (BID), negociados pelo governo federal, examinam-se, no segundo e terceiros governos (1987-1990 e 1991-1994) o processo de negociação e o conteúdo dos projetos especificamente educacionais, diretamente negociados pelo governo estadual com os Bancos. As razões que levaram os dois governos à busca de financiamento externo explicam-se fundamentalmente no quadro da grave crise econômica herdada da ditadura militar, com a consequiente redução dos recursos públicos para as áreas sociais, além de outros motivos que se situam na concepção da educação como formadora de mão-de-obra para o desenvolvimento. O que se pode constatar é que os empréstimos, no caso do Paraná, foram importantes indutores do ajuste progressivo das políticas educacionais, que, nos anos 80, buscaram contemplar a universalização da escola pública, com qualidade, para a maioria da população, ao "pacote" do BIRD, cuja ótica é a racionalidade econômica. Entretanto, não se pode afirmar, por limitações históricas, que houvesse clara compreensão, naquele momento histórico (1983-1990), por parte dos agentes do governo (técnicos e autoridades), do grau de direcionamento das políticas educacionais que resultaria como contrapartida dos empréstimos. A hipótese que pode ser levantada a partir daí é a da plena adesão (identidade) do governo (técnicos e autoridades) que sucedeu aos anteriores às diretrizes dos Bancos.

Palavras-chave: financiamento, educação, Paraná, projetos.

\begin{abstract}
This article presents the results of a research into international financing of World Bank (BIRD) and Interamerican Bank (BID) for elementary and secondary education, in Paraná, during the 80's and 90's, when three governors from Partido do Movimento Democrático Brasileiro (PMDB) were in the head of the State, from 1983 until 1994. It is possible to notice that the first govern (1983-1986) refers and readdresses, according to democratic or communitarian priorities, projects that were financed by external resources (BID), and negotiated by Federal Government. This article also examines, on the second and third governments (1987-1990 and 1991-1994) the negotiation process and the content of educational projects that were negotiated directly
\end{abstract}


by the State Government and the Banks. The reasons that carried those two governs to the external financing can be mainly explained by the economical problems inherited from past military governs, and by the social areas public resources consequently reduction, besides others reasons as the conception of education as workforce training. What is possible to notice is that the loans, particularly for Paraná, were important addressers to the progressive adjust of educational policies, which, in the 80's, tried to contemplate a good quality public school for the majority of the population, to the BIRD policy, that contemplates economical rationality. However, we can not assert, because historical limitations, that there was a clear comprehension, in that specific historical moment (1983-1990), by the side of govern agents (technicians and authorities), of addressing degree of educational policy that were result of the loans counterpart. The hypothesis that can be considered is the one of the plain adhesion (identification) of govern (technicians and authorities), that succeed the past ones to the Banks' directives.

Key-words: financing, education, Paraná, projects.

\section{Introdução}

A temática relativa à presença do financiamento internacional na educação brasileira ocupou parte significativa da produção referente à política educacional de âmbito nacional ou mesmo regional, no caso paranaense, em especial, na segunda metade da década de noventa. Tal processo vem possibilitando tanto a compreensão de suas diversas dimensões e implicações, bem como abrindo um leque de possibilidades investigativas. É nessa segunda dimensão, a das possibilidades investigativas, que se insere a pesquisa relativa ao resgate dos processos por meio dos quais tais financiamentos passam a integrar crescentemente o universo das políticas públicas no campo educativo paranaense.

Assim,

...analisar como vinha se dando o financiamento público do ensino fundamental e médio nos anos 80 , de forma a subsidiar o entendimento da busca de financiamento internacional nos anos 90 e verificar em que medida 
a posição do governo estadual e dos bancos financiadores foram determinantes no efetivo encaminhamento das políticas educacionais que passaram a nortear a ação educativa no sistema público de ensino, ${ }^{1}$

ao se constituírem nos dois maiores objetivos da pesquisa, norteiam o conteúdo do presente artigo, podendo ser considerado como resultado dos esforços realizados pelo grupo de pesquisa envolvido nos estudos da temática do financiamento internacional do ensino paranaense.

Cabe destacar que o referido projeto de pesquisa fez parte do projeto integrado Reestruturação produtiva e as novas formas de trabalho: o novo projeto pedagógico para educação científico-tecnológica proposto pela área de Educação e Trabalho do Programa de Pós-Graduação em Educação do Setor de Educação da Universidade Federal do Paraná, e como tal, incorpora-se no processo de análise das macrocategorias presentes nos processos de escolarização dos contingentes populacionais no presente processo de reestruturação produtiva, fortemente marcado pela exclusão e pela inserção produtiva precarizada.

O presente artigo foi estruturado a partir da consideração das diferentes gestões governamentais que demarcaram a administração pública estadual desde os anos 80, buscando nelas destacar as diferentes formas assumidas pelo financiamento internacional, bem como o papel por ele desempenhado no ensino fundamental ou de nível médio no Paraná. Tal estruturação permitiria recuperar os processos por meio dos quais se deu a presença dos financiamentos internacionais no âmbito da educação e em que medida foram decisivos no encaminhamento das políticas educacionais dos diferentes governos estaduais.

1 cf. Projeto de Pesquisa intitulado: A presença do Banco Mundial e do Banco Interamericano no financiamento do ensino fundamental e médio na rede de ensino estadual do Paraná, nos anos 90. p. 2. 


\section{O primeiro governo peemedebista (1983-1986): o herdeiro}

Cabe relembrar que o contexto da primeira das três gestões sucessivas do Partido do Movimento Democrático Brasileiro (PMDB) no governo do Estado do Paraná estará demarcado pela chamada abertura política, estratégia política dos últimos governos da ditadura militar no país a postergar "o último suspiro", ao menos formal, dado que as forças econômicas e políticas que a compuseram se rearticularam mesmo no contexto da redemocratização política do país, como destaca FERNANDES (1986, p. 1819): "...a ditadura não seria desmantelada e serviria de guia a uma democracia sui generis, que sairia das entranhas do regime, como sangue do seus sangue". E mais:

Não é o governo que pretende impor um "retrocesso". É a estrutura de classes da sociedade civil sob o capitalismo selvagem que não comporta um "avanço". As classes dominantes precisam de um Estado forte para preservar a ordem e reproduzir o seu poder real. (...) Acresce que o capital estrangeiro e as nações imperialistas também temem a "instabilidade política". O que uniformiza (se não unifica) a convergência no tope em favor de um Estado forte, de uma democracia dócil e instrumental aos mais iguais (FERNANDES, 1986, p. 26).

Levadas em conta as considerações de Fernandes, feitas em 1986, os governos de oposição à ditadura militar serão seus herdeiros, quer do legado político quer do econômico. Legados, esses, que transformarão em crise política a crise econômica herdada. Para compreender o contexto da crise política operada na Nova República, importa ter em conta que ela não só herda, mas nela se aprofundam os elementos caracterizadores da crise econômica que já havia se instalado.

.... década perdida entre 80 e 90, com perda do dinamismo econômico, a primeira taxa negativa de crescimento do produto em toda a moderna história econômica brasileira - 4,3\% em 81 -, uma grave crise de acumulação (para o que a dívida externa e seu serviço anual contribuíram poderosamente), a erosão total da capacidade do Estado para proporcionar 
previsibilidade a uma economia complexa (com uma enorme expansão da dívida interna que, se por um lado sustentava a solvabilidade dos capitais privados, por outro reduziu a capacidade de investimento estatal a quase zero, numa economia fortemente induzida pelo comportamento estatal); quase como corolário necessário, a deterioração de todos os serviços públicos, mormente daqueles, mediante os quais o Estado, de certa forma, atendeu crescentes reivindicações populares; (...) sem crescimento econômico, a capacidade redistributiva das políticas sociais se anulou (OLIVEIRA, 1992, p. 30 -31).

Assim, o primeiro governo oposicionista que assume o governo do Estado do Paraná após a ditadura militar, muito embora o tenha feito em nome do compromisso com o "pagamento da dívida social", ${ }^{2}$ produzida pelo modelo econômico da ditadura centrado no desenvolvimento econômico sem fruição social, verá frustradas as possibilidades de realização do compromisso partidário, norteador de sua ação governamental, principalmente em decorrência do comprometimento da capacidade de financiamento estatal.

Apesar de a economia paranaense apresentar, segundo estudos realizados pelo INSTITUTO PARANAENSE DE DESENVOLVIMENTO ECONÔMICO E SOCIAL - IPARDES $(1992 ; 1996)$, relativo dinamismo em relação à economia nacional, com oscilações significativas, especialmente entre 1983 e 1986 e entre 1987 e 1990, e haver alguma melhoria dos índices sociais, particularmente no campo da saúde e educação, não é possível afirmar que o desempenho econômico do Estado tenha correspondido ao enfrentamento do déficit social, apresentando o pior desempenho social entre os estados que compõem a Região Sul. Para demonstrar os reflexos da diminuição da capacidade de financiamento basta tomar uma das políticas setoriais que compunham o plano de ação governamental no campo da educação. As ações governamentais voltadas à expansão e melhoria da rede física faziam parte daquelas orientadas pela política setorial 2, "melhoria da qualidade de ensino com prioridade para a rede pública", mais especificamente pela expressa no item 2.1. "garantia de acesso e permanência do aluno na escola pública". Para tanto, recorremos à uma matéria publicada no Jornal da Educação n. 10 que tem por sugestivo título: $O$ desafio de construir em tempo de crise.

2 PARANÁ. Democracia e justiça social: diretrizes de um programa de governo. Partido do Movimento Democrático Brasileiro - PMDB. Curitiba, 1982. p. 14. 
O conteúdo do texto aponta para uma das medidas que, com sucesso, articulou a instância estadual com a dos municípios. Estratégia que, nesse momento, respondia a uma série de questões como a abertura de frentes de trabalho para parcela da população desempregada, repartição de custos entre instâncias governativas, diminuição dos custos de construção e ampliação física da rede escolar.

Manter o nível de construção, ou até mesmo amplia-lo em tempo de crise, com a escassez de recursos, não parece ser algo fácil. Mas, motivados pela necessidades os técnicos da Fundepar estudaram uma nova sistemática na execução das construções escolares. (...) a nova sistemática consiste em repassar às prefeituras municipais recursos necessários para a execução da obra, projetos (quando solicitados) e orientação para elaboração ou adequação dos projetos pelos municípios. Em contrapartida, as prefeituras administram as construções, organizando ou contratando a mão-de-obra, oferecendo material e artefatos de produção própria.

Esta nova sistemática permitiu a redução significativa nos custos de cada obra, possibilitando o atendimento a um número maior de municípios, além de abrir espaço para novos empregos e motivar a economia local. Com isso, em apenas dois anos e dois meses de Governo, a SEED já entregou à população escolar paranaense 1589 salas de aula (JORNAL DE EDUCAÇão, n. 10, p. 12, 1985).

Outra situação demonstrativa de que o redirecionamento político demarcador da primeira gestão do PMDB, no governo estadual, sofreu delimitações de ordem financeira refere-se ao redimensionamento, em 1983, do Projeto de Apoio ao Pequeno Produtor Rural (Pró-Rural), criado em 1979 e iniciado em 1981, contando com financiamento do Banco Interamericano de Desenvolvimento (BID). Tal projeto, dirigia-se ao atendimento das necessidades mais prementes das áreas economicamente deprimidas do Estado, havendo previsão de ações no campo educativo.

...o subprojeto de Educação até então em execução tinha como pontos básicos: 1- o modelo da escola consolidada - baseada na desativação de uma série de escolas isoladas multisseriadas para a concentração em uma seriada maior e dotada de melhores recursos; 2- processo de amplo 
treinamento de docentes leigos, apoiado na distribuição de material didáticopedagógico; e 3- reequipamento de colégios agrícolas da região (JORNAL DE EDUCAÇÃO, n. 10, p. 4, 1985).

Segundo RAMOS (1987, p.180), que analisou a proposta e a implementação das escolas consolidadas no Estado do Paraná, a nova orientação dada ao Pró-Rural, em 1983, "baseava-se em dois princípios básicos: democratização do poder e ampla participação comunitária." Sob tal orientação foi feita uma avaliação do Pró-Rural por todas as secretarias de estado nele envolvidas, dela resultando o redimensionamento das ações programadas. Após esta redefinição das ações, foram consultados as prefeituras e órgãos municipais e, num terceiro momento, realizou-se consulta aos "produtores rurais (com renda abaixo de US\$ 300 anuais)" das regiões de abrangência do projeto, uma vez que estes produtores rurais tornaram-se sua população alvo. Dessa consulta "surgiram as prioridades da populaçãoalvo: em primeiro lugar a construção de estradas; em segundo, a saúde; em terceiro, a educação; em quarto, a armazenagem e em quinto o fomento agropecuário"(RAMOS, 1987, p. 180).

Para a referida autora, o posicionamento da educação dentre as prioridades revela a aguda necessidade de implementação de medidas voltadas ao escoamento da produção, condição para a sobrevivência, assim como as de atendimento à saúde. Porém, não é só o processo utilizado para a avaliação do projeto ou a localização da educação como terceira prioridade para a população alvo que revela a significativa alteração do projeto: "Deixa de ser prioridade a construção das Escolas Rurais Consolidadas, cujos custos de construção e manutenção são altos, passando a sê-lo a reconstrução e ampliação das escolas existentes (cerca de 300) para aumentar a oferta de ensino nas áreas prioritárias. A participação da comunidade nesta tarefa é enfatizada".

O redirecionamento das prioridades do Pró-Rural, na área de educação, implicou a redução do número de escolas consolidadas. Contudo, as considerações apresentadas por RAMOS (1987), relativamente aos custos de manutenção e à dependência das municipalidades de verbas repassadas pela SEED para tal fim, além da indefinição de quem viria a assumir tais custos após o término do projeto, ajudam a compreender alguns dos determinantes da reconstrução e ampliação das escolas rurais nas áreas priorizadas pelo projeto. 
Foram construídas 36 (das 39 inicialmente previstas) (...) O custo de construção das escolas girou em torno de US\$ 55.000 e US\$ 95.000, cobertos pelo BID. As despesas de manutenção destas escolas são calculadas pelos municípios. Após o exame da SEED, as respectivas verbas são repassadas às Prefeituras Municipais. As quantias variam consideravelmente com base nos seguintes fatores: número de escolas e de pessoas contratadas; volume e espécie de material de consumo; gastos com combustível e gastos diversos. Não existe uma definição sobre quem assumirá a manutenção das escolas após o término do projeto, já que as prefeituras declaram não ter condições de fazê-lo (RAMOS, 1987, p. 180-181).

Das considerações até agora feitas, conclui-se que o primeiro governo de oposição da ditadura no Estado administrará, sob outras prioridades e métodos de decisão e efetivação, os recursos internacionais voltados para o desenvolvimento do setor agrícola que previam ações no campo educativo, em especial para educação rural, e pelo que se deduz das análises de RAMOS (1987) até então indicadas, com autonomia relativa para interferir em suas prioridades e formas de execução. Ou seja, houve, naquele momento histórico, possibilidade de reorientar o uso dos recursos públicos internacionais voltados para o setor agrícola, também no que diz respeito às ações educativas implicadas, embora os contratos de financiamento internacional tivessem tido origem no governo anterior, conforme explicita RAMOS (1987, p. 104; 106), ao se referir ao fato de o processo de construção das escolas consolidadas ter se realizado em duas etapas:

No Brasil elas [as escolas consolidadas] encontraram aceitação durante a vigência do II plano Setorial de Educação e Cultura (1975-1979). A criação do Promunicípio (1975-1979) e do Pró-Rural (1982-1986) tornou possível a construção de 53 escolas consolidadas no Estado do Paraná, através da Fundação Educacional do Paraná - Fundepar, tendo como agente financeiro o Estado, o Fundo Especial - FNDE, o Banco Interamericano de Desenvolvimento - BID e Banco do Brasil no caso do Pró-Rural.

Desta forma, a criação das escolas consolidadas respondia, na primeira fase, à "expansão do ensino de $1 .^{\circ}$ grau, particularmente nas sedes dos municípios, tendo em vista as consequiências do êxodo rural intenso 
ocorrido no Estado", promovida por meio da intensificação das relações estado/município, quer pela via do financiamento da rede física, quer pela assistência técnica sistemática voltada à gestão municipal da educação (RAMOS, 1987, p. 94-95). Na segunda fase, pela via do Pró-Rural, como já se apontou anteriormente, mudam-se as orientações e procedimentos de execução das metas redefinidas adequando-os, como também já se indicou ao novo quadro político e econômico da realidade paranaense.

Cabe considerar ainda que o primeiro governo peemedebista no Estado do Paraná, aplicou recursos internacionais voltados ao financiamento da educação técnica, contratados pelo governo federal a partir do IV Acordo MEC/BIRD - Programa de Melhoria do ensino Agrícola e Industrial - Edutec (1980-1984), cuja duração de sua execução foi prorrogada até o ano de 1990.

Segundo ROMAGNANI (2002, p. 64), o IV Acordo MEC/BIRD foi realizado "na modalidade de ajustamento setorial (Sector Adjustment Loan) voltado a créditos para a agricultura", porém, "nesta modalidade, o empréstimo pode ser estendido a outros setores, como foi o projeto para a educação técnica - Edutec". O referido projeto destinava-se, segundo os componentes do financiamento, à construção, aquisição de materiais e equipamentos, formação de pessoal e elaboração de estudos, tendo sido os dois primeiros os que carrearam a maior parte dos investimentos, muito embora, no Paraná, o convênio entre MEC/SEED tenha tido por objetivo "a melhoria de desempenho das escolas técnicas" (ROMAGNANI, 2002, p. 65). Desta forma, segundo a referida autora os componentes materiais e equipamentos teriam maior expressão, particularmente no caso do Instituto Politécnico Estadual, em Curitiba. A partir de tais informações, evidencia-se que, também no caso do Edutec, o primeiro governo peemedebista pós-ditadura militar administrará recursos de empréstimos contratados pelo governo federal voltados para a área agrícola que previam ações voltadas para o campo educativo, agora relativos à melhoria de desempenho de escolas de ensino técnico. Ou seja, o governo estadual não contrata diretamente o empréstimo voltado para o desenvolvimento do setor primário dominantemente, ainda que na condição de participante, também no projeto voltado à melhoria do ensino técnico, corrobore com as decorrências em termos do endividamento externo.

Segundo FONSECA (1995, p. 187-188), do total dos recursos previstos para o projeto nacional, uma parte considerável, em torno de $20 \mathrm{mi}$ lhões de dólares (aproximadamente 35\% do crédito) foi cancelada em 1991, 
sendo que "dos 45,4 milhões de dólares estimados, o projeto custou 61,4 milhões ao país, dado que o custo total foi aumentado de $35 \%$ em decorrência de dificuldades e atrasos em sua execução".

Em decorrência do exposto é possível afirmar que a primeira gestão peemedebista pós-ditadura militar do governo do Estado do Paraná, relativamente à participação dos financiamentos externos na direção posta nas políticas educacionais, esteve na condição de herdeira de contratos estabelecidos pela esfera federal a serem invertidos dominantemente no setor primário da economia, mas que previam ações no campo da ação educativa. Porém, especialmente no caso dos recursos destinados à educação no meio rural, houve intervenção governamental no direcionamento do projeto, no seu conjunto, com significativas mudanças no que tange às ações no campo educativo como demonstra a análise empreendida por RAMOS (1987), embora o novo direcionamento do Pró-Rural tenha sido determinado pelos reflexos na economia paranaense da grave crise nacional que marcou os anos iniciais da década de 1980, considerada por FIORI (1997, p. 156) a recessão econômica mais séria desde os anos 30, sendo que tão somente nos dois últimos anos da gestão 1983-1986 foram perceptíveis indicadores de recuperação da atividade econômica regional. Desta forma, é possível afirmar que a participação do financiamento externo relativamente à direção dada às políticas educacionais do Estado do Paraná no período correspondente à primeira gestão peemedebista (1983-1986) tem relevância enquanto recursos adicionais aos do tesouro estadual, dado o contexto econômico que marcou o período, porém, os recursos externos não se constituíram em empréstimos diretamente contratados a partir de decisões do grupo político que assumiram o governo estadual naquele período. Assim, enquanto herança, os recursos decorrentes dos financiamentos externos, já contratados, foram administrados tendo em vista não só as condições concretas, igualmente herança da direção dada aos recursos públicos pelos governos militares, assim como, as direções políticas definidas pelo partido político, em especial quanto ao compromisso de resgate da divida social, dívida que foi igualmente herança gerada pelo modelo de desenvolvimento econômico sem fruição social administrado no período militar. 


\section{O segundo governo peemedebista (1987-1990): o contexto das primeiras negociações com o BIRD}

Ao considerar o período correspondente ao segundo governo peemedebista (1987-1990), importa referi-lo ao contexto da economia brasileira nos anos 80, considerado por BALTAR, DEDECCA e HENRIQUE (1996, p. 91) "um momento particular da história brasileira", isto porque a crise econômica, permanente e prolongada, redefiniu os condicionantes da situação social do país. Se a crise econômica, "de caráter estrutural, traduziuse em estagflação com aceleração inflacionária recorrente", o processo de redemocratização demarcou igualmente a evolução da pobreza. Ou como afirma OLIVEIRA (1992, p. 30), a Nova República transformou a crise econômica, herdada da ditadura militar numa crise geral do Estado. Seria impossível imaginar que não haveria reflexos deste contexto por de sobre a economia regional, ainda que o início da gestão correspondesse a um momento de recuperação da atividade econômica estadual. Porém, ao final da gestão, em 1989, segundo análise do gasto público realizada pelo IPARDES (1992, p. 75-76), "o gasto total da administração direta do Estado, foi de $59 \%$, superior ao de 1980 , enquanto a receita permaneceu praticamente estável no período, provocando um déficit de balanço, crescente a partir de 1987, sendo que em 1989, esse foi de cerca de 35\%".

As afirmações anteriores são suficientes para demonstrar que no período marcado pela redemocratização da sociedade brasileira, quando a sociedade ansiava por ver o redirecionamento, pelo Estado, dos recursos públicos, tendo em vista dar concreção às demandas sociais, encontravase ele, o Estado, dilapidado, para usar uma expressão cunhada por OLIVEIRA (1992), pela estatização da dívida externa privada promovida ainda no último governo militar.

Considerada a especificidade da economia regional pode-se dizer que a atividade econômica não demonstrou, no período, tendência inequívoca. Porém, "a confrontação da participação média dos gastos sociais em relação do Produto Interno Bruto do Paraná com a média dos gastos sociais nos governos estaduais no PIB do Brasil, entre 1985 e 1989, demonstra que a do Paraná era inferior, 3,2\% contra 4\%" (IPARDES, 1992, p. 75). Ou seja, a crise econômica ao cavar uma separação entre Estado e sociedade promoveu o aprofundamento da pobreza. Ao lado destes aspectos relativos às implicações decorrentes do quadro econômico nacional junto ao desempenho da economia regional, importa considerar o impacto que a 
reforma tributária, promovida pela Constituição de 1988, teve na receita disponível no Estado que, segundo BARATTO (1990, p. 5) "seria de 17,4\%. Nos municípios o incremento potencial sobre as receitas anteriormente disponíveis seria, em média de 31,1\% nos municípios menores, de 25,2\% nos municípios maiores e de $29 \%$ nos municípios intermediários”. Tal condicionamento contribuiu para que no âmbito da administração estadual fossem estabelecidas medidas voltadas à compensação dos determinantes presentes junto à disponibilidade de recursos. Dentre as medidas assumidas pelo governo estadual no período (1987-1990), particularmente na educação, verificou-se um longo processo de definição de estratégias de transferência do custeio do ensino nas séries iniciais do ensino fundamental, nas modalidades regular, supletiva e especial, para as administrações municipais e a busca de financiamentos externos. ${ }^{3}$

Relativamente à busca de financiamento externo, o programa específico da Secretaria de Estado da Educação (SEED) a ser viabilizado com os recursos externos (BIRD) denominou-se Programa de inovação em Educação Básica (PARANÁ, 1988a). Seu componente principal era o Ciclo Básico de Alfabetização, um "continuum" de dois anos, que faria frente à reprovação e repetência nas séries iniciais, com a utilização de um contra turno para atender as dificuldades de aprendizagem das crianças.

Como objetivo geral da proposta constava “...viabilizar a proposta política consubstanciada na garantia a todas as crianças e jovens paranaenses de acesso ao ensino público de $1 .{ }^{\circ}$ Grau e da extensão de sua permanência no sistema de ensino" (PARANÁ, 1988a, p. 1).

O Programa previa a expansão da rede (construção de salas de aula), complementação alimentar, melhoria da saúde escolar, material didático e equipamento escolar e contratação/capacitação de professores. Incluíamse ainda, como componentes do Programa, a expansão da educação pré-escolar e a expansão da educação especial, bem como o treinamento técnico do pessoal envolvido tendo em vista garantir o acompanhamento, controle e avaliação do Programa.

3 Em virtude da "maior crise das finanças públicas em toda a história brasileira" (entrevista com o governador Dias) o governo Álvaro Dias estimulou a busca de financiamento externo para investimento em alguns programas das Secretarias de Estado. O Paraná, desde o final de 70 e, especialmente, nos anos 80, tornou-se um bom cliente (bom pagador!) do BIRD quando de outros empréstimos, por exemplo, para as áreas rural (Pró-Rural, Paraná Rural) e urbana (Pram, Pedu e, mais tarde, o Prosam). Antes ainda, nos anos 70, os bancos BID e BIRD haviam financiado a construção de usinas e de rodovias. 
A duração prevista para o projeto era de 5 anos (1989-1993) e os custos orçados em U\$\$ 56 milhões, sendo U\$ 26 milhões relativos ao empréstimo do Banco Mundial e U\$\$ 30 milhões referentes à contrapartida estadual (PARANÁ, 1988a).

As negociações da SEED com o BIRD para a definição dos projetos e do montante do empréstimo ocorreram em 1988 e início de 1989, por meio de duas missões (uma exploratória e outra de orientação), prevendo-se a vinda da missão de avaliação da proposta para o início de 1989 (ZABOT, 2000; CASTOR, 2001).

Naquela mesma época, o BIRD iniciou as negociações com a SEED de São Paulo e, estando bem mais avançados os encaminhamentos paulistas, o Banco recomenda à SEED do Paraná seguir alguns procedimentos já realizados pela SEED de São Paulo (BIRDSALL, 1988).

O conjunto destas recomendações orientava-se na direção da priorização dos primeiros anos do ensino fundamental para a melhoria de sua eficácia. Deste modo, tanto a pré-escola como a educação especial, previstos na proposta do Paraná, não poderiam ser contemplados. Também no que tange às construções escolares o Banco indicava a necessidade de que os custos unitários das salas de aula devessem ser reduzidos significativamente de modo a adequarem-se aos padrões do BIRD para a construção de sala de aula para a América Latina (BIRDSALL, 1988). Pode-se perceber que desde então as orientações para empréstimos, que prevalecerão nos anos 90, como, por exmplo, a focalização, já começam a ser esboçadas.

É interessante verificar que foram exatamente os três estados (São Paulo, Paraná e Minas Gerais), onde, no final da Ditadura Militar os partidos de oposição venceram, no caso o PMDB, os escolhidos, nos anos 1990, para receberem o financiamento do BIRD. Estes mesmos estados, nos anos 80, destacaram-se no cenário educacional brasileiro por criarem medidas e políticas educacionais (seguindo as orientações gerais do partido) que visavam, ainda que com dificuldades e contradições, o acesso e a permanência com qualidade (por isso foram criados programas contra a repetência e evasão) da maioria da população na escola pública, o que implicaria em aumento dos recursos públicos, como também a maior participação da população na escola, pela gestão democrática (com eleições e conselhos escolares). De todo modo, cabe indagar: estas políticas e medidas foram usadas e resignificadas em face das prioridades do BIRD, na sua ótica economicista (custo/benefício) e da orientação neoliberal do Estado brasi- 
leiro nos anos 90, ambas adequadas, em última análise ao novo momento econômico? ${ }^{4}$

Os entendimentos da SEED com o BIRD foram facilitados no Paraná, naquele momento, pelo relacionamento profissional que o então Secretário da Educação já tivera com o BIRD como Secretário de governos anteriores, e também devido ao fato de um consultor do Banco, João Batista de Araújo, que veio a ser posteriormente um dos intelectuais orgânicos das Reformas Educacionais do governo Fernando Henrique Cardoso, ter orientado algumas das ações da SEED que aconteceram naquele período no Paraná, antes que se generalizassem como políticas do governo federal, como por exemplo, os exames de avaliação do rendimento escolar das quartas e oitavas séries do, então, ensino de $1 .^{\circ}$ grau, realizadas em nível estadual, e executadas pela Fundação Carlos Chagas de São Paulo e que seriam destacadas pelas missões do BIRD como fatores positivos, pois estavam adequados às suas diretrizes. ${ }^{5}$

Ainda que o BIRD sinalizasse positivamente quanto à possibilidade do empréstimo para o programa da SEED, sabe-se que o governo Sarney, ao seu final, vetou todos os novos empréstimos estaduais de recursos externos, devido à inflação e ao crescimento da dívida, de sorte que a então proposta da SEED - Inovações na Educação Básica (PARANÁ, 1988a) -, não caminhou para a aprovação final, não tendo contado também com suficiente empenho do governo estadual com vistas à sua aprovação.

A troca de Secretário da Educação, ocorrida no final da gestão Álvaro Dias que, na aparência, deveu-se às questões decorrentes da greve dos professores, mas que poderia ser atribuída às dificuldades gerenciais sentidas pelo então Secretário, dada a não priorização, pelo governo Dias, da

4 A escolha dos três estados para receberem financiamento do BIRD poderia ser atribuída ao know how prévio adquirido pelos mesmos nos diferentes programas de enfrentamento da repetência escolar, que já haviam desenvolvido, indicando, assim, a possibilidade de constituírem seus programas, a partir do financiamento externo, em "casos exitosos", muito apreciados para constarem nos relatórios do banco, gerando efeito demonstração?

5 Na gestão Lerner (1995-2001), João Batista Araújo esteve no Paraná novamente, para sugerir ao governo novos encaminhamentos de políticas educacionais. Os jornais locais noticiaram suas afirmações quanto a não haver correlação significativa entre o salário do professor (no caso aumento) e a qualidade de ensino, o que deve ter deixado o sindicato dos professores do Paraná (APP/Sindicato), em campanha salarial, bastante satisfeito! Importa destacar que tal consideração faz parte do receituário do BIRD (e de suas pesquisas), como indica TORRES (1998, p. 166). 
educação básica e sim das obras infra-estruturais e da agricultura, pode ser considerada também fator explicativo da lacuna que haverá entre estas primeiras negociações e o momento seguinte dos novos contatos na busca de financiamentos externos, já no governo Requião (1991-1994). ${ }^{6}$

De todo modo, é preciso registrar na história da educação brasileira que já tiveram início em 1987/1988, também no Paraná, as negociações com o BIRD, uma vez que este fato é desconhecido dos próprios educadores paranaenses que estudam o assunto e não consta da literatura sobre a questão. DE TOMMASI (1998, p. 202), por exemplo, ao analisar os projetos do BIRD em implementação, data o início das negociações no Paraná em 1992 e 1987, em São Paulo, o que não ocorreu, pois foram negociações feitas quase que paralelamente, apesar de, no caso do Paraná, ter havido mais que descontinuidade, uma verdadeira quebra entre um governo e outro, quanto às propostas pró-financiamentos externos, objeto da terceira parte do presente texto.

Levando-se em conta o exposto, importa dar destaque para o fato de que a decisão política de busca de financiamento externo direto para a educação contou com a crescente precarização do fundo público, de cujo déficit orçamentário ao longo da gestão 1987-1990 é expressão mais acabada, como um expressivo determinante. Contudo, o processo de negociação da contratação do empréstimo já revelava a existência de orientações a serem cumpridas tendo em vista a obtenção dos recursos. Ou seja, não se pode imaginar que a contratação de empréstimos financeiros não implicasse, senão em adesão às orientações da agência internacional de financiamento, ao menos em acatamento de suas sugestões de ajuste da proposta às condições do credor. Porém, a compreensão mais plena de tais implicações pressupõe o período em que os financiamentos externos foram parte constitutiva da oferta pública de educação, ou seja, os anos 90 .

6 DE TOMMASI (1996, p. 196), analisando a falta de informações sobre os projetos financiados pelo BIRD, comenta que estes foram negociados "no seio de cúpulas restritas de funcionários das Secretarias de Educação, junto aos técnicos do Banco". Muito provavelmente este tenha sido o procedimento nessa primeira negociação entre a SEED/PR e o BIRD, ainda no governo Álvaro Dias (1987-1990). 


\section{O terceiro governo peemedebista (1991-1994): Projeto Qualida- de no Ensino (PQE), a Carta Consulta e o Projeto Expansão, Melhoria e Inovação no Ensino Médio do Paraná (PROEM): o financiamento como indutor do ajuste}

Ao analisar o conjunto das entrevistas feitas no decorrer da pesquisa com alguns dos principais participantes das negociações com o BIRD e o BID (Manoel - IPARDES, Sebastiani - Secretaria de Estado do Planejamento, Zabot - Secretaria de Estado da Educação, Passos - Secretário de Estado do Planejamento), no governo Requião, comprova-se que nele um novo processo teve início, sem qualquer articulação com a fase anterior, tanto no que se refere às negociações quanto aos conteúdos dos projetos.

Este novo processo é marcado, especialmente, pelas decisões da Secretaria de Estado do Planejamento, que então era responsável pela elaboração do orçamento, quanto ao papel relevante que a educação deve desempenhar no desenvolvimento do Estado face "à sociedade da informação na qual a capacidade de manejar o conhecimento torna-se fundamental" (PASSOS, 2001).

A busca de financiamento externo para a educação é uma diretriz derivada do entendimento do Secretário de Planejamento à época de que os recursos para as áreas sociais, e especialmente para a educação, só seriam preservados no orçamento do governo pela obrigação da contrapartida; uma garantia, portanto, assegurada pelos contratos internacionais. Isto deveria ser assim, tendo em vista as não superadas dificuldades financeiras que o Estado vinha atravessando.

Entende-se, portanto, que a visão de Estado como elaborador de políticas sociais aceleradoras da capacidade produtiva e da competitividade é o que respaldava, naquele momento, a decisão de buscar o financiamento para a educação nos Bancos Internacionais. A opção inicial da Secretaria de Planejamento era por um investimento focalizado na criação de algumas escolas técnicas (2. ${ }^{\circ}$ grau), ou melhor, centros técnicos à semelhança das escolas de Quebec (Canadá), que o Secretário de Planejamento havia visitado, os quais pudessem formar técnicos de alto nível e prover o Estado de mão-de-obra qualificada em áreas de ponta, interferindo no ainda predominante perfil agrícola do Estado.

As preocupações com o endividamento, ainda que levantadas pelos técnicos, foram dimensionadas como risco necessário, dada a importância da decisão. 
A orientação buscada pela Secretaria de Planejamento, junto ao técnico da Fundap/Iesp de São Paulo, Vicente Rodrigues, ex-funcionário do Ipardes e Alcione Saliba, então técnica do BIRD, ${ }^{7}$ que haviam trabalhado na elaboração do Programa de São Paulo para o $10^{\circ}$ grau, já negociado com o BIRD, foi fundamental para que a Secretaria de Planejamento/PR iniciasse o processo de forma correta, ou seja, com possibilidades de êxito, buscando no BIRD, por primeiro, um financiamento para um projeto relativo ao $1 .^{\circ}$ grau, satisfazendo, assim, uma condicionalidade e as prioridades do BIRD, para posteriormente dirigir-se ao BID solicitando recursos que permitissem o desenvolvimento do Projeto de Ensino Médio, objetivo principal e persistente do Secretário do Planejamento. Por esta razão, após as primeiras decisões e os entendimentos do Secretário de Planejamento com o Secretário de Educação/PR e com os Bancos em 1992, começou a ser delineado o $\mathrm{PQE}$, batizado como Projeto Qualidade no Ensino Público/PR, pelos técnicos do Ipardes/SEED, com a consultoria de Vicente Rodrigues, orientandose pela primeira proposta da Secretaria de Estado de Educação do Estado de São Paulo (SEED/SP) e considerando as demandas e necessidades do Departamento de Ensino de $10^{\circ}$ Grau do SEED/PR, nem sempre bem acolhidas pelas sucessivas missões de técnicos do BIRD.

Deste modo, apenas ao final de 1994, mês de outubro, acontece a aprovação e assinatura por parte do governo do Estado do Paraná e o BIRD do PQE. O projeto recebeu no mínimo duas versões (1992 e 1994), ao longo da negociação e sucessivas proposições dos técnicos do Banco, ficando na versão final (1994), com a "cara" do Projeto de Minas Gerais e não com o de São Paulo, pelo qual se pautara no início do processo. Como afirma DE TOMMASI (1998, p. 205):

O Projeto do Estado do Paraná passou por duas reformulações: a primeira era mais próxima daquela do projeto de São Paulo, incluindo os componentes de pré-escolar e saúde escolar; a segunda é mais próxima daquela do Projeto de Minas.

Parece, portanto, ter acontecido um corte na definição dos projetos, que se produz com a elaboração do Projeto do Estado de Minas Gerais. É importante considerar que assessores desse projeto foram pessoas cujas orientações de política educativa tinham uma significativa concordância

7 Alcione Saliba será mais tarde, na segunda gestão Lerner (1999-2002), Secretária de Estado da Educação do Paraná, dentro da mais "rigorosa"obediência às diretrizes do BIRD. 
com aquelas do Banco. O próprio Walfrido dos Mares Guia Neto, então Secretário de Estado da Educação, foi quem assimilou e reproduziu com mais eficácia no país algumas orientações que caracterizam o discurso do Banco: a importância de investir em educação para sustentar o crescimento econômico, a rentabilidade desse investimento em termos de uma análise de custos-benefícios, a questão da "qualidade total" e da reforma do sistema gerencial para atingir níveis de eficiência comparáveis àqueles das empresas.

Podemos dizer que, de uma forma mais "tradicional" de pensar e implementar projetos educativos, que inclui traços de um modelo anterior (ênfase na construção da infra-estrutura - projetos de São Paulo e do Nordeste), tem se passado a um modelo mais inovador, focalizando as ações em alguns elementos considerados chaves (projetos de Minas Gerais e Paraná).

Para demonstrar comparativamente os componentes dos projetos dos diferentes estados brasileiros (Projetos de São Paulo, do Paraná, de Minas Gerais, do Espírito Santo e Nordeste I e II), DE TOMMASI (1998, p. 203) elabora um quadro, indicando os valores relativos a cada um deles. A partir desse quadro, foi elaborado o que consta a seguir (SANTOS, 2001), comparando a composição dos Projetos de São Paulo (1991) e de Minas Gerais (1994) com o do Paraná (versões 1992, 1993 e 1994).

QUADRO - QUADRO COMPARATIVO DOS COMPONENTES DOS PROJETOS DO BANCO MUNDIAL DOS ESTADOS DE SÃO PAULO, MINAS GERAIS E PARANÁ (EM US\$ MILHÕES)

\begin{tabular}{|c|c|c|c|c|c|}
\hline Componentes & $\begin{array}{l}\text { São Paulo* } \\
\text { Junho } 1991\end{array}$ & $\begin{array}{c}\text { Paraná } \\
\text { Junho } 1992\end{array}$ & $\begin{array}{l}\text { M. Gerais* } \\
\text { Maio } 1994\end{array}$ & $\begin{array}{c}\text { Paraná } \\
\text { Junho } 1993\end{array}$ & $\begin{array}{c}\text { Paraná* } \\
\text { Outubro } 1994\end{array}$ \\
\hline Total & 600 & 300 & 302 & 168,252 & 198,4 \\
\hline Melhoria da rede física & 343,226 & 130 & 49,9 & 75,763 & 75,4 \\
\hline Capacitação & 17,442 & 50 & 57,2 & 39,017 & 27,1 \\
\hline $\begin{array}{l}\text { Livros didáticos e material } \\
\text { pedagógico }\end{array}$ & 80,442 & 52 & 121,6 & 20,785 & 75,5 \\
\hline Merenda escolar & 18,731 & - & - & - & - \\
\hline Educação pré-escolar & 70,354 & 18 & - & - & - \\
\hline $\begin{array}{l}\text { Desenvolvimento } \\
\text { Institucional }\end{array}$ & 7,984 & 9 & 68,9 & 11,264 & 18,0 \\
\hline Saúde ao escolar & 31,980 & 7,8 & - & 8,958 & \\
\hline $\begin{array}{l}\text { Avaliação e disseminação do } \\
\text { projeto }\end{array}$ & 3,620 & 1,5 & \# & \# & 2,4 \\
\hline Gerenciamento do projeto & 1,748 & 1,5 & 4,5 & 4,474 & \# \\
\hline Inovações educacionais & - & - & $\#$ & - & \# \\
\hline $\begin{array}{l}\text { Estudos, pesquisa e } \\
\text { avaliação }\end{array}$ & - & - & - & 8,000 & \\
\hline Contingência & - & 30 & - & - & \\
\hline
\end{tabular}

Legenda:

* Apresentados por DE TOMMASI (1998, p. 203)

$\square$ Retirados das propostas do Projeto Qualidade do Ensino Público do Paraná (1992-1993)

- Não há

\# Incluído em outro componente 
$\mathrm{Na}$ análise que DE TOMMASI (1998) realiza relativamente aos componentes dos Projetos dos Estados que obtiveram financiamento do BIRD, destaca-se, de comum a todos eles:

- focalizar as primeiras séries do ensino fundamental (p. 203);

- destinar-se uma parte importante dos recursos para material pedagógico (p. 205);

- prever recursos para a construção e/ou reforma de escolas, mesmo sendo este um componente indicado como não prioritário nas definições estratégicas do Banco (p. 199);

- incluir no componente desenvolvimento institucional a reestruturação da gestão, o fortalecimento dos sistemas de avaliação e de informação (p. 199-200);

- prever a capacitação, o treinamento de professores, dirigentes escolares, técnicos e funcionários das Secretarias (p. 206);

- previsão de influir na relação Estado municípios (p. 206);

- prever estudos sobre os impactos de diferentes medidas no rendimento escolar dos alunos (p. 204);

- prever a divulgação dos resultados desses estudos (p. 204).

Com relação ao Projeto do Estado do Paraná, a autora indica as seguintes características:

- 90\% dos recursos são destinados ao ensino fundamental (p. 204);

- os recursos previstos para o financiamento de material pedagógico são equivalentes àqueles destinados para a melhoria da rede física (p. 205);

- o Banco requer que o Estado se responsabilize pelo fornecimento dos livros às escolas independentemente do cumprimento de suas obrigações por parte do Governo Federal (p. 206);

- o apoio à municipalização caracteriza a influência na relação estado e municípios (p. 206);

- visa-se, também, apoiar a descentralização para as escolas de algumas das competências da Secretaria (autonomia escolar); 
- o componente inovações educacionais prevê o financiamento direto para escolas que apresentem projetos inovadores (em particular no combate à repetência), estabelecendo uma forma de competição entre as escolas e introduzindo, desta forma, no sistema educativo, os valores de eficiência do mercado (p. 206).

A apresentação desse conjunto de características dos projetos dos diferentes estados que obtiveram financiamento do BIRD teve por finalidade, tão somente, indicar que para se ajustar às exigências do financiamento externo o projeto do Paraná sofreu alterações significativas ao longo de, praticamente, toda a negociação na gestão Requião. Importa destacar que na forma final, o projeto do Paraná já indicava, com maior clareza, sua adequação às prioridades do Banco que estão expressas no documento Prioridades y estratégias para la educación (1995). No componente, inovações educacionais, por exemplo, a competição entre as escolas, que mais tarde gerou prêmios de excelência, já estava indicada.

Entretanto, cabe afirmar que, naquele momento histórico, não era possível ainda dimensionar-se as implicações que decorreriam da concessão dos empréstimos quanto ao direcionamento de políticas educacionais subordinadas a uma racionalidade econômica e privatista.

Faz-se necessário destacar também que o governo que elaborou e negociou o PQE não pode executá-lo, pois, em 1994, houve mudança na gestão governamental, sendo de oposição ao governo anterior, a equipe técnica que irá implementá-lo. Assim, "o projeto passou por uma análise criteriosa da nova equipe, que buscou formas de alterá-lo em alguns aspectos, mediante negociação com o Banco Mundial" (SILVA, 1999, p. 73).

Apenas a guisa de exemplo, é possível verificar que no componente 2 - capacitação de recursos humanos - do PQE (gestão Requião), havia a previsão de

capacitação de todos os professores de $1 .{ }^{\circ}$ Grau das duas redes de ensino, em 80 horas anuais, distribuídas em quatro fases, integralizadas por meio de cursos, participação em grupos de estudo e educação à distância. É de se considerar que esta proposta de capacitação, à época, foi fortemente questionada pelos técnicos do Banco, mas manteve-se no componente por insistência da direção do projeto. No entanto, a nova direção da SEED, que assumiu em 1995, imprimiu orientação completamente diferente à 
capacitação docente, com destaque à realização de seminários de massa, na Universidade do Professor, em Faxinal do Céu (SILVA, 1999).

Se as prioridades do Banco já se encontravam presentes nas propostas do $\mathrm{PQE} / 94$, ainda que mescladas com as orientações fortemente publicistas e universalizantes da SEED/PR, a nova gestão que assumirá a SEED, em 1995, buscará orientar suas políticas de modo a que o receituário do BIRD, a lógica gerencial e a minimização dos custos para o poder público fossem o norte orientador das ações educacionais desenvolvidas, conforme foi observado nas análises críticas contidas em inúmeras dissertações, teses e artigos de intelectuais paranaenses, que tomaram como objeto de investigação as políticas educacionais do Paraná, especialmente nos anos 90/2000, dentre elas: GONÇALVES, 1994; SILVA, 1998; HIDALGO, 1998; SANTOS, 1998; RECH, 1999; SILVA, 1999.

No que tange ao financiamento para um programa de ensino médio, o caminho percorrido foi outro e as implicações do financiamento para o delineamento de políticas "adequadas" ao novo momento econômico-político só apareceram, especificamente, no governo Lerner, que não foi objeto específico deste estudo.

A gestão 1991-1994 não chegou a completar a definição de um Programa para o ensino médio em todo o seu detalhamento no período da gestão. A possibilidade de negociação do financiamento externo recebería sinalização positiva da Comissão de Financiamentos Externos da Secretaria de Planejamento do governo federal, em maio de 1993; tal autorização foi dada a partir da apresentação, em fevereiro de 1992, da "Carta Consulta do Projeto Expansão, Melhoria e Inovação do Ensino Médio do Paraná' elaborado pela Secretaria do Planejamento e Coordenação Geral com a colaboração de técnicos da SEED/PR" (SILVA, 1999, p. 136).

O BID, neste ínterim, já havia tomado conhecimento do documento paranaense e da liberação do Governo Federal.

Em maio de 1994, em Washington, uma missão técnica do Estado manteve as primeiras negociações com o BID e, em dezembro de 1994, os técnicos do BID efetivaram a Primeira Missão de Identificação no Paraná para verificar os primeiros delineamentos do Programa. ${ }^{8}$ Nestas reuniões,

8 Todas as informações sobre o encaminhamento do Proem, foram retiradas de SILVA, S. T. Proem: a adequação do ensino médio do Paraná ao novo regime de acumulação capitalista. Curitiba, 1999. Dissertação (Mestrado) - Programa de Pós-Graduação do Setor de Educação da Universidade Federal do Paraná. 
além dos membros do governo (Secretaria de Planejamento e da Educação) e dos técnicos, já participaram membros da equipe de transição e o futuro Secretário de Planejamento do novo governo.

O programa, na sua versão preliminar, contida na Carta Consulta, visava "a expansão e melhoria qualitativa do sistema público de 2. grau", com as seguintes diretrizes:

a) ações dirigidas à qualidade de ensino em termos de formação geral;

b) estruturação e modernização de cursos técnicos de nível médio voltados às atividades dos setores secundário e terciário;

c) implantação de espaços educativos vinculados à criação e difusão pedagógica de ciência e tecnologia;

d) implementação de Centros Avançados de formação de professores para o ensino fundamental.

Eram previstos cinco componentes, três deles destinados à criação de centros regionais, Centros Públicos Regionais de Ensino Técnico, Centros de Ciência e Tecnologia (Cecitec) e Centros Avançados de Formação de Professores para o ensino fundamental.

A criação dos centros (como havia proposto o Secretário de Planejamento) era o coração do programa, tomando U\$ 130 milhões, dos U\$\$ 200 milhões previstos para todo o projeto.

A previsão de realização de estudos sobre o ensino médio foi feita na Carta Consulta, já incluída no PQE, para que o programa pudesse ser completado com dados mais fidedignos sobre a realidade.

A Secretaria de Planejamento assumiu a coordenação da elaboração do programa com a presença na equipe de técnicos da SEPL, do Ipardes e do Cefet. A presença do representante do Cefet visava uma melhor articulação com o setor produtivo, conforme recomendação do BID (SILVA, 1999, p. 138).

Até este momento, final de 1994, o dimensionamento do Projeto Expansão, Melhoria e Inovação no Ensino Médio do Paraná parecia caminhar na direção proposta inicialmente pela Secretaria de Planejamento, com ênfase na criação de Centros Públicos Regionais de Ensino Técnico e a possibilidade de uma reorganização geral do Ensino Médio geral e 
profissionalizante em todo o Estado do Paraná ${ }^{9}$ com expansão, a partir das demandas regionais e novas modalidades, conforme registra o primeiro documento (Plano de Ação) do Departamento de Ensino de Segundo Grau - Desg, em 1995, que data da época em que foi mantida, embora por pouco tempo, a mesma chefia.

Entretanto, a partir da substituição da chefia do Desg começaram a ocorrer transformações radicais na proposta de ensino médio geral e profissionalizante do Paraná, sendo que este último praticamente se extingue a partir de 1996, na rede pública estadual, que apenas mantém a, então chamada, educação geral, no $2{ }^{\circ}$ Grau.

Um novo perfil deste nível de ensino foi se configurando e se expressou definitivamente no Proem, elaborado pelas novas equipes, técnicos do novo governo, ou por aqueles que foram "convertidos" pelo discurso da necessária privatização da formação técnica por meio da Agência para o Desenvolvimento do Ensino Técnico no Paraná (Paranatec), cuja proposta e ações ainda não foram devida e criticamente examinadas em estudos e pesquisas.

A versão definitiva do Programa de Expansão, Melhoria e Inovação no Ensino Médio do Paraná - Proem, teve sua execução iniciada em 1998 e encontrava-se, segundo SILVA (1999), em perfeita consonância com as orientações do BIRD, tanto no que tange à educação geral, como quanto à educação profissional.

O estudo específico do BIRD sobre "Educación técnica y formación profissional" (BANCO MUNDIAL, 1992) contém as diretrizes fundamentais que orientaram tanto as opções do Paraná quanto as do governo brasileiro quanto à educação profissional. Entre elas, a opção pela formação geral (ensino médio) e a educação profissional baseada em competências e organizada por módulos de ensino, além do entendimento de que só por exceção a formação profissional pode ser feita pelo poder público, devendo dela se encarregar a iniciativa privada.

O estudo de SILVA (1999) contém um exame crítico, de excelente qualidade, de todo o Programa Proem elaborado sob responsabilidade do

9 “A definição política do governo do Estado do Paraná, de reformas para o desenvolvimento do ensino médio no Estado na sua totalidade e de propor a sua reorganização em novas bases através de um Programa específico foi bem aceita" (SILVA, 1999, p. 141). Além disso, os recursos financeiros, segundo a mesma autora, seriam os primeiros específicos e suficientes para a melhoria das condições do ensino médio no Paraná. 
governo Lerner, servindo de referência sobre o tema, dado que não se constitui objeto específico da presente pesquisa.

Pode-se afirmar, no entanto, que a proposta para o ensino médio paranaense, elaborada na Carta Consulta (versão preliminar), era bastante diferente e quase oposta ao Proem em sua versão de 1995. Visava-se, na primeira proposta, a ampliação e a melhoria da qualidade, ainda que sob a lógica da formação de técnicos de nível médio e ou de professores para a educação infantil e fundamental, em centros públicos.

O Proem extinguiu, praticamente, a formação de técnicos e de professores, em nível médio, na rede pública, abrindo mais campo à expansão da rede privada de formação técnica, por meio da Paranatec, beneficiando, com recursos públicos a formação de mão-de-obra especializada, especialmente para empresas privadas, como por exemplo, os convênios para oferta de cursos para montadoras de automóveis.

De posse dos elementos constitutivos do processo por meio do qual se tornou efetiva a presença de financiamentos internacionais para o ensino fundamental e médio no Paraná, é possível considerar seu significado mais pleno, muito embora tenha sido sua efetiva realização executada após 1995, por um governo, em duas gestões governamentais sucessivas, cuja configuração ideológica conservadora permitiu, favoreceu ao menos, a realização da concepção educativa explicitamente orientada pelas agências internacionais de financiamento. Porém, a opção pela contratação do empréstimo internacional para financiar diretamente a educação e o longo processo de formulação e reformulação do PQE foram, contraditoriamente, responsabilidade do terceiro governo peemedebista. Contraditoriamente, sim, pois, tal processo, representou a forma pela qual se deu, ainda na vigência do terceiro governo peemedebista, o esvaziamento do conteúdo pautado pelas políticas públicas orientadas pelos princípios democráticos universalistas para o ajuste, o mais possível, às orientações das agências internacionais de financiamento pautadas pela lógica economicista, pela correlação custo/ benefício, além de estarem voltadas à busca de outros financiadores privados para partilharem com o Estado o custeio.

Assim, pode-se considerar que de 1983 a 1994 as gestões de governo peemedebista expressaram, regionalmente, o movimento que se pôs, quer para o Brasil, quer para a maioria dos países latino-americanos, submetidos ao crescimento exponencial de suas dívidas externas, que, ao fim e ao cabo dos anos 80 , condicionou a adoção das orientações de corte neoliberal pela via da negociação com as agências internacionais de financiamento. Segundo FIORI (1997, p. 211-212), 
...nossos países aderiram às idéias neoliberais em grande parte constrangidos por suas dívidas externas, e a partir daí pelas decorrências lógicas dos seus novos planos de estabilização desenhados em torno do modelo originalmente experimentado no México e sustentados na sobrevalorização cambial, nas taxas de juros e na abertura comercial. Neste sentido, há que se compreender que se transforma numa consequiência direta e quase inapelável desta opção o fato de que nossos governos nacionais tenham aberto mão de qualquer possibilidade de exercício de uma política macroeconômica, monetária ou fiscal, mais ativa. Em síntese, esta opção estratégica de corte neoliberal já nos retirou (...) quase todo o espaço de exercício das políticas públicas.

Tal processo, de forma cruel, se realizou exatamente no momento em que nossos países, para usar a forma de dizer de Fiori, experimentavam após "completarem maioridade" autoritária, 21 anos de regime ditatorial, a possibilidade de expressarem publicamente as mazelas sociais produzidas no período de desenvolvimento econômico sem fruição social, por julgarem ter chegado a hora de controlar o Estado com vistas a redirecionar socialmente o fundo público. Não sabíamos, ainda, enquanto países periféricos, que as novas exigências para a reprodução ampliada do capital já reorientavam o uso do fundo público até nos países de bem-estar social. Como humanos, porém, não dispomos da capacidade de antever o movimento da história. Necessitamos participar dela e a partir dela compreender os processos nos quais estamos envolvidos para nos situarmos em relação a eles. Assim, foi necessário uma década para apreendermos plena e profundamente as mudanças que estiveram se configurando no conjunto das relações sociais e suas implicações para o plano regional e local. Contudo, a imediata, assim como a futura configuração de nossas sociedades, das possibilidades de enfrentamento das consequiências excludentes do processo no qual estamos envolvidos, assim como de sua necessária superação, continuarão sendo a pimenta no molho da vida possível. 


\section{REFERÊNCIAS}

BALTAR, P. E. de A.; DEDECCA, C. S.; HENRIQUE, W. Mercado de trabalho e exclusão social no Brasil. In: OLIVEIRA, C. E. B. de; MATTOSO, J. E. L. (Orgs.). Crise e trabalho no Brasil: modernidade ou volta ao passado? São Paulo: Scritta, 1996. p. 87-108.

BANCO MUNDIAL. Educación técnica y formación professional. Washington DC., 1992.

BANCO MUNDIAL/DEPARTAMENTO DE EDUCACIÓN Y POLÍTICAS SOCIALES. Prioridades y estrategias para la educación. Washington DC., 1995.

BARATTO, G. Impacto da reforma tributária na receita dos municípios do Paraná. Análise Conjuntural, Curitiba, ano 1, v. 12, p. 1-3, jan. 1990.

BIRDSALL, N. Carta ao Secretário da Educação Dr. Belmiro Valverde Jobim Castor. Washington: Divisão de População e Recursos Humanos do Departamento de Países da América Latina e Região do Caribe do Bird, 1988.

CASTOR, B. V. J. Entrevista do Secretário de Estado da Educação, nos anos 1987 e 1988, concedida ao grupo de Pesquisa sobre "A presença do Banco Mundial e do Banco Interamericano no financiamento do ensino fundamental e médio na rede pública de ensino estadual do Paraná, nos anos 90”. Curitiba, 2000.

DE TOMMASI, L.; WARDE, M. J.; HADDAD, S. (Orgs.). O Banco Mundial e as políticas educacionais. 2. ed. São Paulo: Cortez, 1998.

DIAS, A. Entrevista do Ex-Governador de Estado do Paraná, gestão 1987-1990, concedida ao grupo de Pesquisa sobre "A presença do Banco Mundial e do Banco Interamericano no financiamento do ensino fundamental e médio na rede pública de ensino estadual do Paraná, nos anos 90”. Curitiba, 2001.

FERNANDES, F. Nova República? 3. ed. Rio de Janeiro: Zahar, 1986.

FIORI, J. L. Neoliberalismo e políticas públicas. In: FIORI, J. L. Os moedeiros falsos. Petrópolis: Vozes, 1997.

FONSECA, M. O Banco Mundial e a Educação: reflexões sobre o caso brasileiro. In: GENTILI, P. (Org.). Pedagogia da exclusão:o neoliberalismo e a crise da escola pública. Petrópolis:Vozes, 1995. p. 169-195.

GONÇALVES, M. D. de S. Autonomia da escola e neoliberalismo: Estado e escola pública. São Paulo, 1994. Tese (Doutorado em Educação) - Faculdade de Educação, Pontifícia Universidade Católica de São Paulo. 
GONÇALVES, M. D. de S. et al. A presença do Banco Mundial e do Banco Interamericano no financiamento do ensino fundamental e médio na rede pública de ensino estadual do Paraná, nos anos 90. Curitiba, 2000. Projeto de pesquisa, mimeog.

HIDALGO, A. M. Tendências contemporâneas da privatização do ensino público: o caso do Estado do Paraná. São Paulo, 1998. Dissertação (Mestrado) - Faculdade de Educação, Pontifícia Universidade Católica de São Paulo.

INSTITUTO PARANANENSE DE DESENVOVIMENTO ECONÔMICO E SOCIAL (IPARDES). Situação social da população do Paraná. Curitiba: Ipardes, 1992.

INSTITUTO PARANAENSE DE DESENVOLVIMENTO ECONÔMICO E SOCIAL (IPARDES). Balanço e perspectivas da descentralização: o caso do Paraná 1987-1994. Curitiba: Ipardes, 1996.

JORNAL DE EDUCAÇÃO. Curitiba: SEED-PR, n. 8, jan./fev. 1985.

JORNAL DE EDUCAÇÃO. Curitiba: SEED-PR, n. 10, maio/jun. 1985.

MANOEL, M. Entrevista concedida pela técnica do Ipardes ao grupo de Pesquisa sobre "A presença do Banco Mundial e do Banco Interamericano no financiamento do ensino fundamental e médio na rede pública de ensino estadual do Paraná, nos anos 90". Curitiba, 2000.

OLIVEIRA, F. de. Collor, a falsificação da ira. Rio de Janeiro: Imago, 1992.

PARANÁ. Democracia e justiça social: diretrizes de um programa de governo. Partido do Movimento Democrático Brasileiro - PMDB. Curitiba, 1982.

. Inovações na educação básica. Missão do Banco Mundial, 14 a 16 de março de 1988. Memória. Curitiba: SEED-PR, 1988b.

. SECRETARIA DE ESTADO DA EDUCAÇÃO. Programa de inovação em educação básica. Curitiba: SEED-PR, 1988a. Mimeog.

PASSOS, C. A. K. Entrevista do Secretário de Estado do Planejamento da gestão 1991-1994, concedida ao grupo de Pesquisa sobre "A presença do Banco Mundial e do Banco Interamericano no financiamento do ensino fundamental e médio na rede pública de ensino estadual do Paraná, nos anos 90”. Curitiba, 2001.

RAMOS, L. M. P. de C. As escolas consolidadas paranaenses: mito e realidade. Curitiba, 1987. Dissertação (Mestrado) - Setor de Educação, Universidade Federal do Paraná.

RECH, P. E. Faxinal do Céu: Universidade do Professor. A redução dos conceitos de educação e uma ameaça à sua forma pública e democrática. São Paulo, 1999. 
Dissertação (Mestrado em Educação) - Faculdade de Educação, Pontifícia Universidade Católica de São Paulo.

ROMAGNANI, P. A trajetória da educação profissional no Instituto Politécnico Estadual: transpondo o muro da escola. Curitiba, 2002. Dissertação (Mestrado em Educação) - Setor de Educação, Universidade Federal do Paraná.

SANTOS, J. M. T. P. As políticas governamentais para o ensino fundamental no Estado do Paraná diante dos preceitos da Constituição. São Paulo, 1998. Tese (Doutorado em Educação) - Faculdade de Educação, Universidade de São Paulo.

. As condições do financiamento público e a direção dada às ações governamentais para o ensino fundamental no Estado do Paraná 1983 a 1994. In: HIDALGO, A.; SILVA, I. (Orgs.). Educação e Estado: as mudanças nos sistemas de ensino do Brasil e Paraná na década de 90. Londrina: Ed. UEL, 2001.

SEBASTIANI, L. E. Entrevista do assessor do Secretário de Estado do Planejamento na gestão 1991-1994, concedida ao grupo de Pesquisa sobre "A presença do Banco Mundial e do Banco Interamericano no financiamento do ensino fundamental e médio na rede pública de ensino estadual do Paraná, nos anos 90”. Curitiba, 2000.

SILVA, I. L. F. Reforma ou contra-reforma no Sistema de Ensino do Estado do Paraná? Uma análise da meta da igualdade social nas políticas educacionais dos anos 90. São Paulo, 1998. Dissertação (Mestrado) - Faculdade de Educação, Universidade de São Paulo.

SILVA, S. T. da. Proem: Programa Expansão, Melhoria e Inovação no Ensino Médio do Paraná: uma política de ensino adequada à nova forma de acumulação capitalista. Curitiba, 1999. Dissertação (Mestrado em Educação) - Setor de Educação, Universidade Federal do Paraná.

TORRES, R. M. Melhorar a qualidade da educação Básica? As estratrégias do Banco Mundial. In: DE TOMMASI, L.; WARDE, M. J.; HADAD, S. (Orgs.). $O$ Banco Mundial e as políticas educacionais. 2. ed. São Paulo: Cortez, 1998.

ZABOT, N. Entrevista pelo técnico da Secretaria de Estado da Educação concedida ao grupo de Pesquisa sobre "A presença do Banco Mundial e do Banco Interamericano no financiamento do ensino fundamental e médio na rede pública de ensino estadual do Paraná, nos anos 90”. Curitiba, 2000.

Texto recebido em 25 maio 2003

Texto aprovado em 05 set. 2003 